\title{
Kernos
}

Revue internationale et pluridisciplinaire de religion grecque antique

$11 \mid 1998$

Varia

\section{Corinne BONNET, Astarté. Dossier documentaire et perspectives historiques}

\section{Vinciane Pirenne-Delforge}

\section{OpenEdition \\ Journals}

\section{Édition électronique}

URL : http://journals.openedition.org/kernos/1269

DOI : 10.4000/kernos. 1269

ISSN : 2034-7871

\section{Éditeur}

Centre international d'étude de la religion grecque antique

\section{Édition imprimée}

Date de publication : 1 janvier 1998

ISSN : 0776-3824

\section{Référence électronique}

Vinciane Pirenne-Delforge, « Corinne BONNET, Astarté. Dossier documentaire et perspectives

historiques », Kernos [En ligne], 11 | 1998, mis en ligne le 16 juin 2011, consulté le 22 septembre 2020.

URL : http://journals.openedition.org/kernos/1269 ; DOI : https://doi.org/10.4000/kernos.1269 
s'y point engager. Jetons donc au vent, sans plus, l'idée de semailles futures » (p. 170). Un défi qu'il importe de relever.

Corinne Bonnet

(FNDP Namur - Pontificio Istituto Biblico)

Corinne Bonnet, Astarté. Dossier documentaire et perspectives bistoriques, Roma, CNR, 1996. 1 vol. $21 \times 31 \mathrm{~cm}, 169$ p., 12 pl. (Collezione di Studi Fenici, 37. Contributi alla Storia della Religione Fenicio-Punica, 2). ISBN : 88-8011-053-5.

Après un important travail sur Melquart, l'« Héraclès » phénicien (Studia Pboenicia, 8), c'est au dossier difficile d'Astarté, l' « Aphrodite » phénicienne, que s'intéresse $\mathrm{C}$. Bonnet dans cet ouvrage dont la majeure partie reprend les sources qui nous informent sur la déesse avant de passer à une réflexion synthétique en fin de parcours. L'introduction attire l'attention sur une série de questions fondamentales qui constituent les «enjeux » de ce dossier : la difficulté de dessiner une origine déterminée à cette figure divine, sa place exacte dans les panthéons phénico-puniques, son adaptation au monde nouveau des colonies, ses relations aux déesses gréco-romaines qui en constituent l'interpretatio, son iconographie problématique.

Outre la Phénicie, son berceau historique, Astarté apparaît en maints endroits du reste du Proche-Orient, en Égypte, à Chypre, en Grèce, à Carthage et dans l'Afrique du Nord au sens large, en Italie, à Malte et en Espagne : autant de chapitres d'un parcours documentaire dont l'A. est attentive à replacer lès témoignages souvent hétéroclites et éclatés dans leur contexte historique. Mais c'est avec le dernier chapitre que cette dimension historique prend sa pleine mesure en une brève synthèse qui tente de résoudre les problèmes posés d'entrée de jeu. Les antécédents historiques d'Astarté, tout d'abord. La documentation ne permet pas d'éclairer en continu l'image d'une Astarté "pré-phénicienne » que l'A. ne perçoit que par «flash». L'omniprésence d'Astarté dans le monde phénico-punique est une donnée nouvelle en regard de ce que l'on peut percevoir des panthéons antérieurs, notamment à Ugarit, aux $\mathrm{III}^{\mathrm{e}}$ et $\mathrm{II}^{\mathrm{e}}$ millénaires. Ses relations avec Inanna/Ishtar sont envisagées, mais dépasser le constat d'une analogie reviendrait à forcer la documentation dont on dispose.

Ses relations avec Aphrodite, par contre, offrent une assise plus large et sont susceptibles d'intéresser beaucoup les spécialistes de la religion grecque. La problématique des origines est délicate, l'A. le souligne, et je l'avais volontairement éludée dans mon ouvrage sur L'Apbrodite grecque (Kernos, Suppl. 4). Toutefois, la confrontation des deux dossiers permet de reposer le problème, quitte à se contenter de «bonnes» questions, que l'A. ne manque pas de poser dans cet ouvrage. Nous avons d'ailleurs repris le problème dans une recherche conjointe à paraître dans la Collection de l'Institut historique belge de Rome.

La dimension iconographique de la recherche est abordée à la fin de l'analyse, pour en appeler à l'étude de ce matériel si ambigu par des spécialistes des images, un domaine en pleine évolution. L'A. fournit également le dossier des textes épigraphiques phénico-puniques mentionnant Astarté et un dossier récapitulatif de ses attestations, de même qu'un aperçu de l'onomastique phénicopunique contenant le théonyme Astarté. L'ouvrage est illustré de planches en noir et blanc dont la qualité contraste avec le nombre d'erreurs matérielles qui émaillent l'édition de ce livre. Sa qualité aurait mérité davantage de soin, à l'image du bel ouvrage de l'A. sur Melqart. 